\title{
Recurrent Urinary Tract Infection Revealing an Acquired Para-Ureteral Diverticulum after Renal Transplantation: Case Study
}

Omar Jendouzi ${ }^{1 *}$, Aya Sobhi ${ }^{2}$, Abdelali Bahadi $^{2}$, Mohamed Alami ${ }^{1}$, Driss Elkabbaj ${ }^{2}$ and Ahmed Ameur ${ }^{1}$

${ }^{1}$ Department of Urology, Faculty of Medicine and Pharmacy, Mohammed V Military Teaching Hospital, Rabat, Morocco

${ }^{2}$ Department of Nephrology, Hemodialysis and Renal Transplantation, Faculty of Medicine and Pharmacy, Mohammed V Military Teaching Hospital, Rabat, Morocco

\begin{abstract}
Renal transplantation (RT) is considered to be the best substitute treatment for end-stage renal failure. Urologic complications occur in $4 \%$ to $8 \%$. A delay in detection and treatment of any of these complications may lead to loss of renal graft function, morbidity of patients. One of the most frequent complication is Vesico Ureteral Reflux. We report a case of a young transplant patient, presented with a singular complication of RT: grade III vesicoureteral reflux associated to an acquired postoperative paraureteral diverticulum, discussing the clinical and therapeutic aspects of this complication.
\end{abstract}

Keywords: Renal transplantation; Vesicoureteral reflux; Paraureteral diverticulum

\section{Introduction}

Renal transplantation (RT) is considered to be the best substitute treatment for end-stage renal failure. With improved transplantation technology and new immunosuppressive agents, 1-year survival rates for grafts are reported to be between $80 \%$ and $95 \%$, depending on the type of the graft used. The half-life of grafts from living related donors varies between 13 and 24 years, depending on the match [1]. However, despite all these improvements, postoperative complications still do occur in approximately $12-20 \%$ of patients [2].

These complications can be divided into 3 categories: vascular, urologic, and nephrogenic. A delay in detection and treatment of any of these complications may lead to loss of renal graft function, morbidity, or even the patient's death [3].

Urologic complications occur in $4 \%$ to $8 \%$ of patients and include ureteral obstruction, urine leak, peritransplant fluid collections (hematomas, lymphoceles, abscesses), whilst vascular complications occur in approximately $1 \%$ to $2 \%$ [4].

Among urologic complications of kidney transplantation, we find Vesico Ureteral Reflux (VUR) that is a pretty common complication that should be treated whenever it becomes symptomatic to avoid its impact on the graft.

We report a case of a young transplant patient, presented with a singular complication of RT: grade III vesicoureteral reflux associated to an acquired postoperative paraureteral diverticulum, discussing the clinical and therapeutic aspects of this complication.

\section{Patient and Observation}

24-year-old female patient, with TCKD (terminal chronic kidney disease) discovered in 2008 due to an unknown nephropathy (late diagnosis, no kidney biopsy was performed), having in her medical history a sibling undergoing chronic dialysis due to lithiasic nephropathy.

The patient was put under conventional dialysis on September 2010 using a left cephalic AVF (arterio venous fistula) as a vascular access.

5 years later (in 2015), she was subject to a kidney transplantation from a related living donor (her mother); the transplanted kidney was placed extraperitoneally in the patient's right iliac fossa, with end- to-side anastomosis of renal artery to external iliac artery. To restore urinary drainage a ureteroneocystostomy was performed; a procedure by which the ureter is implanted directly into the dome of the bladder.

No immediate, acute or subacute complications were reported and the outcome of the surgery was favorable as:

- The resumption of immediate renal function: nadir of creatinine at $9 \mathrm{mg} / \mathrm{l}$ at postoperative day 12 (POD12).

- No externalized hemorrhage was observed.

- Stable Hemodynamics, normal graft ultrasound and doppler at POD1.

- Bladder catheter retrieval has been done at POD6, and the patient was released at POD 10 .

The 2 first years following renal transplantation showed no sign of complication: patient asymptomatic, creatinine level between 9 and 13 $\mathrm{mg} / \mathrm{l}$, blood levels of immunosuppressive therapy in the normal range.

Then, at M25 (25 months postsurgery), the patient was admitted with classic pyelonephritis presentation: fever $39^{\circ} \mathrm{C}$, pain and tenderness of the right iliac fossa and dysuria, which was confirmed by positive urine cytobacteriological examination (UCBE) to E. coli. This urinary tract infection (UTI) resolved after proper antibiotic treatment using 3th generation cephalosporin (3GC) and gentamicin at the cost of an increase of creatinine at $15 \mathrm{mg} / \mathrm{l}$

Since that episode, our patient presented three other similar UTI episodes two to E. coli, and one to Klebsiella pneumoniae that resolved after antibiotherapy adapted to the antibiogram, but caused also a decline in kidney function to $23 \mathrm{mg} / \mathrm{l}$ of creatinine.

*Corresponding author: Jendouzi O, Department of Urology, Faculty of Medicine and Pharmacy, Mohammed V Military Teaching Hospital, Rabat, Morocco, Tel: +212669185144; E-mail: jendouziiomar@gmail.com

Received: August 14, 2019; Accepted: September 28, 2019; Published: Octobe 03, 2019

Citation: Jendouzi O, Sobhi A, Bahadi A, Alami M, Elkabbaj D, et al. (2019) Recurrent Urinary Tract Infection Revealing an Acquired Para-Ureteral Diverticulum after Renal Transplantation: Case Study. J Nephrol Ther 9: 335.

Copyright: () 2019 Jendouzi O, et al. This is an open-access article distributed under the terms of the Creative Commons Attribution License, which permits unrestricted use, distribution, and reproduction in any medium, provided the original author and source are credited. 
To investigate these recurrent UTI, we performed a Retrograde UrethroCystography (RUC) that revealed right grade III vesicoureteral reflux (VUR) with no other associated abnormalities (Figure 1); which we treated using submucosal endoscopic injection of macroplastics (Polydimethylsiloxane); this procedure involves submucosal injection of a bulking agent into the bladder wall below the ureteral orifice, or within the ureteral tunnel, to provide tissue augmentation.

Unfortunately, the procedure failed to correct the VUR; as control RUC showed persistent reflux of the same severity and revealed a paraureteral diverticulum (Figure 2) that we thought was probably linked to the frequent recurrence of the urinary infection.

In the light of these findings, surgical exploration has become essential; we then performed an anti-reflux open surgery that involved re-implanting the right ureter into the bladder using Lych-Gregoire technique to increase its intramural length at the ureterovesical junction.

During the intervention, a pretty large paraureteral diverticulum was discovered (Figure 3) allowing us to perform a diverticulectomy.

The postoperative course was uneventful; especially no new episode of UTI was reported over the course of 8 months, with stabilized renal function at $20 \mathrm{mg} / \mathrm{l}$ of creatinine.

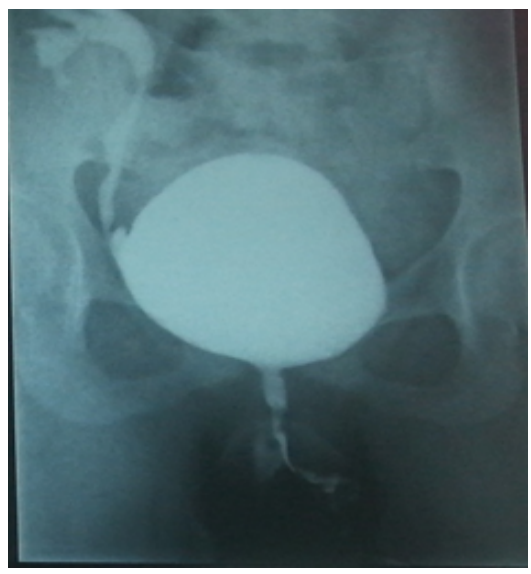

Figure 1: Retrograde Urethrocystography revealing right grade III vesicoureteral reflux.

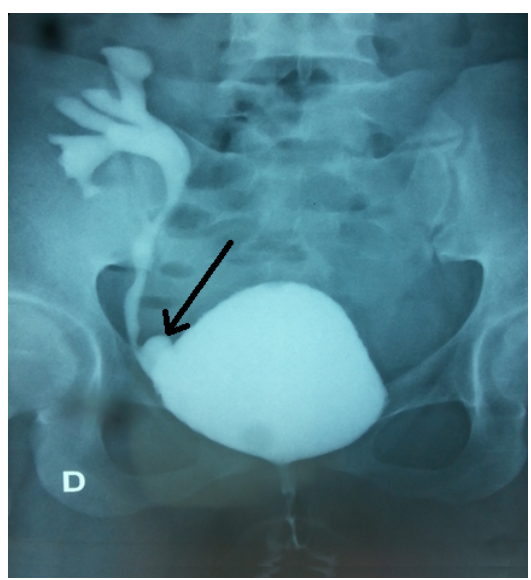

Figure 2: Control Retrograde Urethrocystography unilateral grade III vesicoureteral reflux in addition to a paraureteral diverticulum.

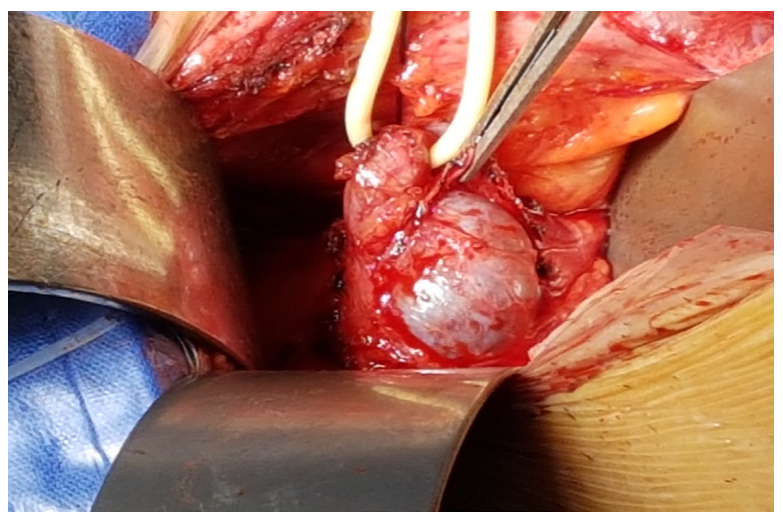

Figure 3: Para ureteral diverticulum discovered during surgical exploration

\section{Discussion}

The treatment of choice for patients with end stage renal disease is renal transplantation. Despite improvements in peritoneal dialysis and hemodialysis, these patients survive better and much longer after receiving a kidney transplant. Survival rates have improved because of refined surgical techniques and more effective immunosuppression [4].

However, complications have been reported: urologic, vascular and nephrogenic.

Pertaining urologic complications; they have a prevalence of 2.6$13 \%$, often affect the distal third of the ureter, and result in graft loss in $10-15 \%$ of cases $[5,6]$. They are commonly secondary to the alterations in ureteral vascularization during graft manipulation, which causes vascular impairment and subsequent necrosis. Approximately $2 / 3$ of the early urologic complications is apparent in the first month after transplantation and are treated by the transplantation team [7].

The most common urologic complications are urine leak or urinary obstruction, however other less common urologic complications may occur such as infection, abscesses, hematomas, lymphoceles.

Vesicoureteral reflux (VUR) into the transplanted kidney occurs frequently after transplantation. However, the effect of VUR on both early and late graft function and graft survival remains unpredictable [8].

In our case, vesico ureteral reflux was discovered along with a paraureteral diverticulum. Paraureteral diverticulum is a rare urological condition that could be either congenital or even less commonly, acquired: secondary to the presence of ureteral calculi [9] or as a complication of surgery $[10,11]$.

Ureteral diverticula are sub-classified into three categories: 1) abortive ureteral duplications (a blind- ending bifid ureter); 2) true congenital diverticulum containing all tissue layers of the normal ureter; 3) acquired diverticulum representing mucosal herniation $[12,13]$.

Diverticula can present with painless hematuria [14-16] or be entirely asymptomatic and present as an incidental finding on imaging $[12,16,17]$. In our case, we think that the diverticulum made the bed of recurrent UTI.

Diverticulectomy with segmental resection of the ureteral diverticulum with an end-to-end anastomosis is currently advocated in cases where the urine refluxes and stagnates, causing urinary tract infection $[18,19]$ which is the procedure we opted for. 
Citation: Jendouzi O, Sobhi A, Bahadi A, Alami M, Elkabbaj D, et al. (2019) Recurrent Urinary Tract Infection Revealing an Acquired Para-Ureteral Diverticulum after Renal Transplantation: Case Study. J Nephrol Ther 9: 335.

Page 3 of 3

Most recently, successful laparoscopic resection of acquired ureteral diverticula has been described by li and al in 2006 [20].

The general prognosis of untreated, uncomplicated ureteral diverticula is excellent $[16,17,21]$ however there have been reported cases of some adverse events.

The occurrence of TCC (Transitional cell carcinoma) in a lower ureteral diverticulum has been described [22] and perforation of a diverticulum can also occur. Also, Douglas et al reported on patients who developed hydroureteronephrosis secondary to the diverticulum and were subsequently treated with surgical excision. At 4 year follow up their renal function remained normal with no deterioration on excretory urography $[23,24]$.

In our case, thanks to the diverticulectomy combined to the anti-reflux surgery, no other UTI episode has occurred in the followup period of 8 months with stabilized renal function at $20 \mathrm{mg} / \mathrm{l}$ of creatinine.

\section{Conclusion}

Vesicoureteral reflux (VUR) into the transplanted kidney occurs frequently after transplantation, however its association with an acquired ureteral diverticulum is a rare entity that deserves to be described; especially considering the consequences that entails such as recurrent UTI and decline of the graft function. Hopefully in our case, anti-reflux open surgery associated with diverticulectomy was successful, emphasizing the importance of early recognition and treatment of this type of complications to preserve the graft.

\section{References}

1. Cecka JM, Terasaki PI (1992) The UNOS Scientific Renal Transplant Registry Clin Transplant pp: 1-16.

2. Orons PD, Zajko AB (1995) Angiography and interventional aspects of renal transplantation. Radiol Clin North Am 33: 461-471.

3. Fatih M, Ozkan F, See TC, Tatli S (2014) Renal Transplant Complications: Diagnostic and Therapeutic Role of Radiology. Can Assoc Radiol J 65: 242-52.

4. Akbar SA, Jafri SZH, Amendola MA, Madrazo BL, Salem R, et al. (2005) Complications of Renal Transplantation. Education Exhibit 25: 1335-56.

5. Shoskes DA, Hanbury D, Cranston D, Morris PJ (1995) Urological complications in 1000 consecutive renal transplant recipients. J Urol 153: 18-21.

6. Marzi VL, Filocamo MT, Dattolo E, Zanazzi M , Paoletti MC , et al. (2005) The treatment of fistulae and ureteral stenosis after kidney transplant. Transplant Proc 37: 2516-17.
7. Kocak T, Nane I, Ander H, Ziylan O, Oktar T, et al. (2004) Urological and surgical complications in 362 consecutive living related donor kidney transplantations. Urol Int 72: 252-56.

8. Molenaar NM, Minnee RC, Bemelman FJ, Idu MM (2017) Vesicoureteral Reflux in Kidney Transplantation. Prog Transplant 27: 196-9.

9. Schaad $P$ (1969) Ureteral diverticulum: diagnosis due to a concomitant lithiasis Bull Mem Soc Chir Paris 59: 47-51.

10. Kuzuhara K, Sugimoto H, Takahashi I, Kusaba R, Yamada Y, et al. (1978) Acquired ureteral diverticulum after renal transplantation. Nihon Hinyokika Gakkai zasshi 69: 1660-66.

11. Aragona F, Bassi P, Passerini Glazel G, Pagano F (1989) Acquired intravesical ureteral diverticulum: an unusual late complication of ureteroneocystostomy. $J$ Urol 141: 1420-21.

12. Herndon CD, McKenna PH (2000) Antenatally detected proximal uretera diverticulum. Urology 55: 774

13. Johnin K, Kadowaki T, Kushima M, Koizumi S, Ushida H, et al. (2000) Congenital ureteral diverticulum coexistent with hydronphrosis caused by vascular compression involving the uterine artery and umbilical ligament: report of a case. J Pediatr Surg 35: 1350-52.

14. Sanroma Ortueta I, Fernandez Goenaga JM, Lopez Garcia JA, Garmendia Larrea JC, Arocena Lanz F (1989) Ureteral diverticula: A propos of 2 cases. Archivos espanoles de urologia 42: 466-68.

15. Mori C, Yamada D, Homma $Y$ (2011) A case of calculus in the true ureteral diverticulum. Int J Urol 18: 180-81.

16. Barrett DM, Malek RS (1975) Ureteral diverticulum. J Urol 114: 33-5.

17. Builov VM, Sencha AN (2000) Ureteral diverticulum. Urologiia (Moscow Russia:1999) 2010: 63-65.

18. Cendron J, Saied H, Trottot P (1975) Bifid ureter ending blindly at one of its upper ends: 4 cases. Journal d'urologie et de Néphrologie $81: 775-83$

19. Cope RM, Snow BW (1991) Massive cystic ureteral diverticula in infancy. J Urol 146: 575-77.

20. Li JR, Chiu KY, Lin HM, Cheng CL, Yang CR, et al. (2006) Laparoscopic excision of a ureteral diverticulum. Int J Urol 13: 995-96.

21. Wan YL, Hsieh ML, Hsueh C, Shum HC, Kea CL (1996) Sonographic diagnosis of a ureteral diverticulum. J Ultrasound Med 15: 483-85.

22. Harrison GS (1983) Transitional cell carcinoma in a congenital uretera diverticulum. J Urol 129: 1231-32.

23. Douglas LL, Pott GA (1979) Case report: congenital ureteral diverticulum and solitary kidney. J Urol 122: 401-2.

24. Kayler L, Kang D, Molmenti E, Howard R (2010) Kidney transplan ureteroneocystostomy techniques and complications: review of the literature. Transplant Proc 42: 1413-20. 